\title{
Reflection on Teaching Dance on YouTube: Negotiating Between Maintaining a Culturally Relevant Pedagogy and Participating in the Commercialized Realities of Teaching Dance Online
}

Maïko Le Lay, University of California, Irvine

Keywords: YouTube, online teaching, culturally relevant pedagogy, dance education

Before the pandemic, I was a dance scholar-practitioner in the process of completing my doctoral dissertation on embodied hip hop pedagogies. My research advocates for wider use of embodied and culturally relevant pedagogies in K-12 and higher education in underserved schools in the Inland Empire region of Southern California. In short, I was teaching hip hop dance and culture in underrepresented academic settings and teaching about socio-cultural and socio-political concepts such as cultural appropriation, commodification, positionality, etc. When the stay-at-home order started in California in March 2020, I, like many others could no longer teach face-toface. I knew though, that during the quarantine, youth-especially those from underrepresented communities-would have even fewer opportunities to move and learn about dance cultures. So, I developed a YouTube channel with family-friendly dance and workout video tutorials. Online is where we dance now. Screen-tutoring became my new normal during the pandemic.

In this piece, I examine my transition from teaching dance in-person with my students in academic settings to teaching on YouTube for viewers I don't know and cannot see. I reflect on my negotiation between my teaching ideals based on culturally relevant pedagogies, and institutional barriers to dance education online. For me, teaching dance on YouTube meant both participating in and trying to disrupt neoliberal ideas of education, such as the commercial nature of the very online platform I was using. I present both the benefits and problems associated with pedagogical uses of YouTube and describe how I navigated these two realities.

\section{Difficulties of Sustaining a Culturally Relevant Pedagogy on YouTube}

MiRi Park and Heather Castillo argue that dance and technology have always intersected, yet that the "dance-at-home" necessity gave a push and "stretched" dance 
education positively. ${ }^{1}$ They conclude that stepping out of conservatories and studios enables dancers to re-center dance as a communal and social activity. I knew through my own research and teaching, that most youth today used YouTube regularly to access both academic resources and videos that engaged their personal interests. With that in mind, I was very excited to create dance tutorials on YouTube because I was primarily focused on the accessibility and new possibilities this platform had to offer for online dance teaching.

The term "culturally relevant pedagogy" was coined by education scholar Gloria Ladson-Billing. ${ }^{2}$ It refers to the kind of teaching that places students' cultural identity at the center of learning to transcend the hegemonic culture. I also ground my teaching philosophy in bell hooks' work. She critiques Eurocentric educational practices and advocates for teaching about non-dominant knowledges. ${ }^{3}$ Both scholars suggest that teachers make space for students' critical reflection on their identities, societies, and cultures.

As a dance scholar-educator, I have always been conscious to instruct dance with historical and cultural context by, for example, teaching about the origins of the moves and inviting students to critically think about their evolution. When I teach in person, I structure my lessons so that students both learn the embodied techniques and develop their own creative voices through improvisation. However, while developing my online tutorials, I gradually realized that, while the digitalization of dance made creating and sharing movement more accessible, the economic interests of a platform such as YouTube made it more difficult to pursue a culturally relevant pedagogical structure. In her examination of YouTube-native dance videos, popular dance and media scholar Alexandra Harlig provides a nuanced and critical analysis of commercialization and massive circulation of dance. ${ }^{4}$ Harlig states that the commercial use of dance videos in social media contexts both "subsumes and broadcasts" the innovations of web-native dance communities. She describes that while artists now have a platform to transmit social media-native movements on a large scale, they do so within "longstanding infrastructures that primarily benefit those with preexisting economic and cultural capital, and along lines of class and race..$^{15}$ My YouTube experience matched Harlig's analysis very closely and shed additional light on the complex reality of teaching dance online.

Many difficult dance tutorials already exist on YouTube, so I wanted my channel to appeal to introductory-level movers. Originally, I had created tutorials that lasted around 30 minutes. In that amount of time, I could explain and culturally contextualize movements for beginners. However, I quickly realized that this format of teaching did not work on YouTube. Viewers wanted to receive catchy, quick-to-digest, and fun content all at once, which required me to shorten my videos considerably. According to experts, YouTube contents should be 5 minutes or shorter. ${ }^{6}$ 
Compressing the videos required a lot of soul searching and compromise. My teaching philosophy is about providing context to the movements. Unfortunately, YouTube does not really lend itself to that kind of method because it privileges quick and immediate "how to" instructions. Though some successful YouTubers thrive on longer videos, they are the minority who can afford that approach because they have developed their fan base.

I had to negotiate between creating tutorials which would match my teaching priorities but may never be seen by anyone and creating content that was more attractive to viewers but was not culturally connected. I felt conflicted, both as a dance instructor and scholar. On the one hand, I believed I was helping youth move during the quarantine. On the other hand, I felt like I was reproducing some of the teaching habits that my scholar-self would critique. In the end, I had to find a compromise, and I now wonder whether practicing culturally relevant pedagogy is even possible on YouTube.

\section{Navigating Hypervisibility on YouTube \& Social Media:}

Developing a YouTube channel almost always requires engaging with other digital spaces, such as social media. For that, I had to "get back online" and become visible again. Social media became the marketing platform for my tutorials. At first, I did not feel very comfortable "being out there." I felt that dancing on YouTube was already a big step for me as it made me uncomfortably more visible. Until recently, I was torn between participating in and resisting the marketing imperatives of teaching online and succumbing to the hyper-focus on body images in the online world. However, I soon realized that I could be teaching great, useful content, but if nobody knew about it, then the cycle was broken. And my main goal was to make embodied practices accessible to a wide audience during the quarantine. So, I developed the image and messaging I wanted to portray: cozy, friendly, welcoming, and me-like. If I was going back on social media, I did not want to create picture-perfect scenarios that distanced me from my audience of beginners. The main idea was to create an inviting environment showing that dancing and working out can be accessible and done from the comfort of our living rooms.

I have learned to negotiate my own vulnerability and increased visibility as a female dance educator and a sense of loss of privacy I experienced after "putting myself out there." After I created my YouTube tutorials, I realized that my living room, my accent, my body, and my identity were at the disposal of anyone who comes across my channel or social media accounts. I like to think that my viewers have good intentions and that the few bad experiences I had in the process were exceptions. 


\section{Conclusion}

From this experience, I learned about making YouTube tutorials, marketing my channel and using social media to promote my work. My experience shows the limitations imposed by a commercial online platform on a culturally relevant pedagogical philosophy. That philosophy is usually grounded in deep, genuine, and reciprocal relations between students and teachers. But maintaining such relations with viewers I don't know and cannot see was challenging. Thus, embodied relations do not always translate on screen and can break online. However, the most important lesson has been in negotiating between my stance and convictions as a teacher and the commercial nature of YouTube. My main takeaway from this process was that I had to reconfigure my teaching philosophy and compromise to a certain level to achieve the most important goal-reaching the audience.

\section{Biography}

Dr. Maïko Le Lay is a French and Japanese scholar-practitioner. She currently works as a postdoctoral scholar in the Connected Learning Lab at the University of California, Irvine. Le Lay received her PhD in Critical Dance Studies from the University of California, Riverside. Her doctoral research on embodied hip hop pedagogies advocates for more embodied and culturally sustaining pedagogies in $\mathrm{K}-12$ and higher education classrooms. More specifically, she conducted an ethnography and performed choreographic readings of hip hop events, dance classes, and lectures and examined the tensions between Western and hip hop epistemologies in these Western institutional spaces. Le Lay possesses a MA in Political Science from the Université Catholique de Louvain (UCL, Belgium) and a MA and BA in Media and Cultural Studies from the Université Paris III Sorbonne Nouvelle (France). Le Lay started a YouTube channel during the pandemic to render embodied practices more accessible to wider audiences.

Email: maikolelay@gmail.com

Website: http://www.maikolelay.com

\section{Notes}

' Castillo and Park, "Towards a Mindful Preparedness." 
${ }^{2}$ Ladson-Billings, "Toward a Theory of Culturally Relevant Pedagogy."

${ }^{3}$ hooks, Teaching to Transgress.

${ }^{4}$ Harlig, "'Fresher Than You,'” 50.

${ }^{5}$ Ibid.

${ }^{6}$ Greenfield, "The Internet's Attention Span."

\section{References}

Castillo, Heather and MiRi Park. “Towards a Mindful Preparedness: How Teaching Dance Online in a Crisis Prepares Us for Future Possibilities of Digital Dance Pedagogies in Higher Education." Schlundt Lecture hosted by the UCR Dance Department online on 29 May 2020.

Greenfield, Rebecca. "The Internet's Attention Span for Video Is Quickly Shrinking." The Atlantic. 8 August 2013.

Harlig, Alexandra. "'Fresher Than You': Commercial Use of YouTube-Native Dance and Videographic Techniques." The International Journal of Screendance 9 (2018). 50-71. https://doi.org/10.18061/ijsd.v9i0.6235

hooks, bell. Teaching to Transgress. Routledge, 2014. https://doi.org/10.4324/9780203700280

Ladson-Billings, Gloria. "Toward a Theory of Culturally Relevant Pedagogy." American Educational Research Journal 32.3

(1995): 465-491. 